\title{
Vanadis 4E çeliğinin kaplamasız matkap uçlarıyla delinmesinde kesme parametrelerinin aşınma, yüzey pürüzlülüğü ve talaş oluşumuna etkisi
}

\section{The effect of cutting parameters on wear, surface roughness and chip formation in drilling of Vanadis 4E steel with uncoated drill bits}

\author{
Salih Korucu 1(0), Gürcan Samtaş ${ }^{2 *}$ (1) \\ ${ }^{1}$ Gazi Üniversitesi, Teknoloji Fakültesi, İmalat Mühendisliği Bölümü, Ankara, TÜRKIYYE \\ 2 Düzce Üniversitesi, Mühendislik Fakültesi, Mekatronik Mühendisliği Bölümü, Düzce, TÜRKIYY \\ Sorumlu Yazar / Corresponding Author*: gurcansamtas@duzce.edu.tr \\ Atıfsekli/How to cite: KORUCU S., SAMTAŞ G. (2021). Vanadis 4 E çeliğinin kaplamasız matkap uçlarıyla delinmesinde kesme parametrelerinin \\ aşınma, yüzey pürüzlülüğ̈̈ ve talaş oluşumuna etkisi. DEÜ FMD 23(69), 961-971.
}

Öz

Matkaplar endüstride kullanım ihtiyacına bağlı olarak çeşitli malzeme ve ebatlarda üretilmektedir. Metallerin delinmesinde genel olarak, yüksek hız çeliği (HSS) veya titanyum nitrür (TiN) kaplamalı matkap uçları kullanılmaktadır. Günümüzde CNC freze tezgahlarında delme ișlemleri, hızlı ve doğru bir şekilde yapılabilmektedir. Bu çalışmada Vanadis 4E toz metalürjik çeliğe kaplamasız HSS üç farklı çapta matkap uçları $(6,7.5$ ve $9 \mathrm{~mm})$, üç farklı kesme hızı $(12,13$ ve $14 \mathrm{~m} /$ dak) ve üç farklı ilerleme oranı $(0.075,0.1$ ve $0.15 \mathrm{~mm} / \mathrm{dev})$ kullanılarak delme işlemi gerçekleştirilmiştir. Deneysel tasarım için Taguchi L9 ortogonal dizisi kullanılmış ve her bir deney için delik yüzeylerinden pürüzlülük ölçümleri yapılmıștır. Ayrıca her bir deney sonrası optik mikroskop ile matkap uçlarının așınma durumları ve çıkan talaşlar incelenmiştir. $6 \mathrm{~mm}$ çaptaki matkapta en iyi pürüzlülük değeri $12 \mathrm{~m} / \mathrm{dak}$ kesme hızı ve $0.075 \mathrm{~mm} / \mathrm{dev}$ ilerlemede, $7.5 \mathrm{~mm}$ çaptaki matkapta en iyi pürüzlülük değeri $14 \mathrm{~m} / \mathrm{min}$ kesme hızı ve $0.075 \mathrm{~mm} / \mathrm{dev}$ ilerleme oranında ve $9 \mathrm{~mm}$ çaptaki matkapta en iyi pürüzlülük değeri $12 \mathrm{~m} / \mathrm{min}$ kesme hızı ve $0.15 \mathrm{~mm} / \mathrm{dev}$ ilerleme oranında elde edilmiştir. Aşınmalar incelendiğinde matkap uçlarında yan yüzey ve radyal așınmaların oluștuğu gözlemlenmiștir.

Anahtar Kelimeler: Vanadis 4E, Delme, Yüzey pürüzlülügü, Talaş oluşumu, Aşınma

\section{Abstract}

Drills are produced with various materials and sizes based on their need for use in the industry. Highspeed steel (HSS) or titanium nitride (TiN) coated drill bits are generally used to drill metals. Today, drilling operations can be done quickly and accurately on CNC milling machines. Uncoated HSS drill bits in three different diameters $(6,7.5$ and $9 \mathrm{~mm})$, three different cutting speeds $(12,13$ and 14 $\mathrm{m} / \mathrm{min})$ and three different feed rates $(0.075,0.1$ and $0.15 \mathrm{~mm} / \mathrm{rev})$ were used for drilling operations on Vanadis 4E powder metallurgical steel in this study. Taguchi L9 orthogonal array was used for the experimental design and roughness measurements were made from the hole surfaces for each experiment. Additionally, wear conditions and chip formations of the drill bits were investigated with 
an optic microscope after each experiment. The study found that the best surface roughness value was $12 \mathrm{~m} / \mathrm{min}$ cutting speed and $0.075 \mathrm{~mm} / \mathrm{rev}$ feed rate in $6 \mathrm{~mm}$ diameter drill, $14 \mathrm{~m} / \mathrm{min}$ cutting speed and $0.075 \mathrm{~mm} / \mathrm{rev}$ feed rate in $7.5 \mathrm{~mm}$ diameter drill and $12 \mathrm{~m} / \mathrm{min}$ cutting speed, and 0.15 $\mathrm{mm} / \mathrm{rev}$ feed rate in $9 \mathrm{~mm}$ diameter drill. When the wears were examined, the study observed that lateral surface and radial wears occurred on the drill tips.

Keywords: Vanadis 4E, Drilling, Surface roughness, Chip formation, Wear

\section{Giriș}

Bilgisayar Nümerik Kontrollü tezgahlarda (CNC) delme, kolaylı̆̆ı ve seri üretim açısından yaygın olarak kullanılan bir yöntemdir. CNC delme için en büyük zaman dilimi takım değiștirmeyle geçtiğinden, daha hızlı ișlemler için delik çaplarındaki değişiklik en aza indirilmelidir. Takım ömrü, takımın artık kullanılmadığı gerçek kesme süresidir. Takım ömrünü tanımlamanın birçok yolu vardır ve takım ömrünün sonunu ölçmenin ortak yolu, maksimum kabul edilebilir aşınma sınırlamasıdır. Fakat kaba işlemelerde bu durum farklıdır. Çünkü kaba işlemede işlenen yüzeyin kalitesi önemli olmadığı için takım aşınsa bile işlem süreci devam edebilir. Takım ömrü için belirlenen ölçüt, yüzey kalitesini bozabilecek aşınma durumu ile eş değerdir. Talaşlı imalat operasyonları sırasında oluşan yüksek kesme sıcaklıkları ve buna bağlı olarak meydana gelen takım aşınmaları sıklıkla karşılaşılan problemlerdir. Son yıllarda bu problemleri önlemek ve kesici takım performansını arttırmak amaciyla yeni teknolojiler üzerine çalışılmaktadır. Geliștirilen takım teknolojileri daha çok takım geometrisi, takım kaplaması ve takım malzemesi konusundadır. $\mathrm{Bu}$ özellikler imalat prosesini oldukça etkilemektedir [1]. Delme ișleminde, kesme parametrelerinin yanlış seçimi, delik kalitesini olumsuz etkilemektedir. Bundan dolayı, delme işleminde, yüzeyin hassas olarak işlenmesi için bu parametrelerinin iyi belirlenmesi gerekmektedir [2].

Endüstride kullanılan talaş kaldırma yöntemlerinin amacı, artan talaș miktarı ile birlikte yüksek işleme doğruluğu ve daha düşük yüzey pürüzlülüğü elde etmektir [3]. Sert işlenebilirlik özelliklerine sahip malzemelerin işlenmesinde mevcut geleneksel üretim yöntemleri, takım așınması ve ișleme süresi gibi ekonomik olmayan işleme çıktılarına neden olur [4]. Kesici takımlar için takım ömrünün artması, imalat endüstrisinde önemli bir ekonomik faktördür [5]. Literatür incelendiğinde delinebilirlik konusunda birçok çalıșma yer almaktadır. Kriyojenik işlem delinebilirlik çalışmalarında performansı arttırma yönünde matkaplara uygulanan etkili yöntemlerden biridir. Çiçek vd. kriyojenik işlem uygulanmış AISI D2 takım çeliğini M35 matkaplarla delerek, kriyojenik işlemin takım ömrü, takım aşınması, mikro yapı ve mikro sertlik üzerine etkilerini araştırmıșlardır [6]. Matkaplarda kullanılan geometri delik kalitesine doğrudan etkisi olup, delme performansını etkilemektedir. Yavuz vd. GGG 50 malzemesi farklı matkap geometrileri ve kesme parametreleri kullanılarak delmişlerdir. Deneysel tasarımda Taguchi metodu kullanılmış ve deneysel sonuçlar ilerleme kuvveti, giriş-çıkış yüzey pürüzlülüğü, dairesellikten sapma ve diklikten sapma olarak değerlendirilmiştir [7]. Kıvak vd. AISI 316 paslanmaz çeliği kaplamalı HSS matkaplarla delinmesinde kesme parametrelerinin, delik çapları, dairesellik ve talaş oluşumu üzerine etkilerini araştırmışlardır [8]. Yağmur vd. AISI 1050 çeliğinin delinebilirlik performansını araştırmışlardır. Deneysel tasarım için Taguchi Metodu kullanılmış ve 18 adet deney yapılmıştır. Deneylerde çıkış parametresi olarak kesme kuvvetleri ölçülmüş ve kesme parametreleri optimize edilmiștir. kaplamalı ve kaplamasız matkaplarla yürütülen deneylerde ilerleme oranı arttıkça sabit kesme hızında, itme kuvvetlerinde artış olduğu gözlemlenmiștir [9]. Yağmur vd. delik delme ișlemlerinde kesme parametrelerinin kesme bölgesindeki sıcaklığa etkisini deneysel olarak incelemişlerdir. Çalışmalarında AISI 1050 çeliğine kaplamalı ve kaplamasız matkaplarla delme işlemleri uygulamışlardır. Çalışmalarında kaplamalı kesici uç ile yürütülen deneylerde delme bölgesinde sicaklıklar önemli ölçüde düşmüștür [10]. Literatürde özellikle çelik malzemelerin delinebilirliği, farklı kaplamaya sahip matkap uçlarının performanslarının incelenmesi, delme işleminde kesme parametrelerinin optimizasyonu ve kompozit malzemelerin delinebilirliği üzerine çalıșmalar da mevcuttur [11-20]. 
DEÜ FMD 23(69), 961-971, 2021

Literatür incelendiğinde Vanadis $4 \mathrm{E}$ toz metalurjik çeliğin delinmesine yönelik bir çalışma olmadığı görülmüştür. Bu çalışmada Vanadis 4E çeliğine üç farklı çapta kaplamasız HSS matkap uçları, üç farklı kesme hızı ve üç farklı ilerleme kullanılarak delme işlemleri gerçekleştirilmiştir. Deney tasarımı için Taguchi L9 ortogonal dizi kullanılmış ve toplamda 9 deney yapılmıștır. Deneyler sonrası delinen yüzeylerden pürüzlülük ölçümü yapılmış ve her bir deney sonrası matkapların yan yüzeyleri ve uçlarından aşınma görüntüleri alınarak dış köșe ve radyal așınmalar incelenmiștir. Her bir deney sonrası çıkan talaş oluşumları fotoğraflanmış ve bu oluşumlar değerlendirilmiştir. Ayrıca kesme parametrelerinin yüzey pürüzlülüğü üzerine etkileri varyans analizi ve üç boyutlu grafiklerle değerlendirilmiştir.

\section{Materyal Metod}

\subsection{Delme deneyleri}

Calışmada kesici takım olarak; HSS, DIN 338 normunda, $118^{\circ}$ uç açısına sahip üç farklı çapta
(6, 7.5 ve $9 \mathrm{~mm})$ matkaplar kullanılmıștır. Delme işlemleri First MCV-300 CNC dik işleme merkezinde gerçekleştirilmiştir (Şekil 1).
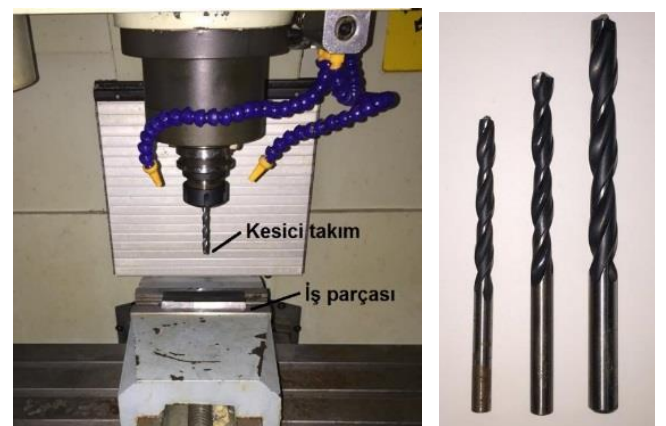

Sekil 1. Deneysel tasarım ve kesici takımlar

Delinecek malzeme için Uddeholm firmasına ait 80x80x30 mm ölçülerinde Vanadis 4 Extra toz metalurjik takım çeliği kullanılmıștır. Kullanılan malzemeye ait mekanik ve yapısal özellikler Tablo 1'de gösterilmiştir [21].

Tablo 1. Vanadis 4E çeliğine ait mekanik ve yapısal özellikler

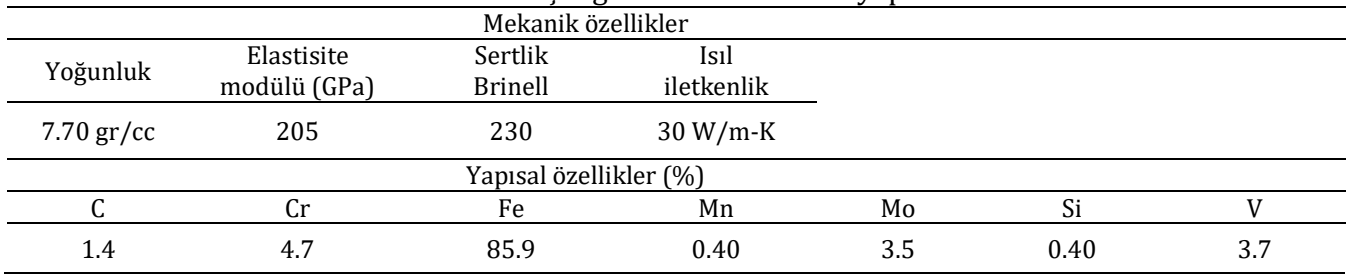

\subsection{Yüzey pürüzlülük ölçümü}

Yüzey pürüzlülük ölçümleri Mitutoyo SJ-301 model yüzey pürüzlülük cihazı ile yapılmıștır (Șekil 2). Taguchi L9 ortogonal dizisi kullanılarak toplam 9 deney yapılmış, pürüzlülük ölçümleri, deliklerin başından ve sonundan olmak üzere iki defa tekrarlanmıştır. $\mathrm{Bu}$ çalışmada bu ölçümlerin ortalaması kullanılmıștır.

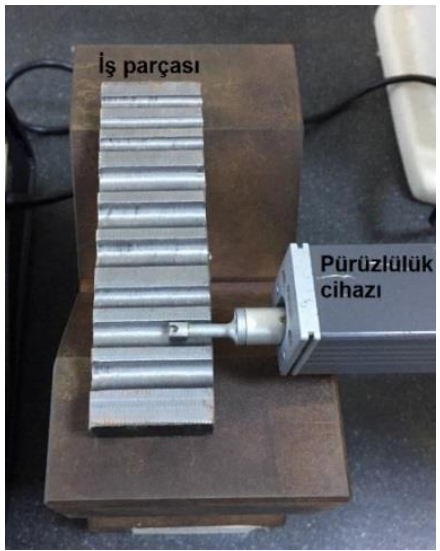

Şekil 2. Pürüzlülük ölçümleri 


\subsection{Aşınmaların incelenmesi}

Her bir delme deneyi sonrası matkap uçlarının dış köșe ve radyal aşınmalar incelenmiştir. İncelemelerde Nikon Eclipse LV150N model mikroskop kullanılmıștır.

\subsection{Deneysel Çalışmalar}

Bu çalışmada Vanadis 4E toz metalürjik çeliğe üç farklı çapta matkap ucu kullanılarak delme işlemi uygulanmıştır. Deneysel tasarımda Taguchi L9 ortogonal dizisi kullanılmıș, toplamda 9 deney yapılmıștır. Her bir matkap ucu için üç deney yapılmıştır. Kesme parametrelerinin belirlenmesinde, Uddeholm Vanadis 4E'ye ait katalog bilgilerinden faydalanılmıştır [21]. Deneylerde bor yağı kullanılarak islak delme işlemi gerçekleştirilmiştir. Deneyler sonrası malzeme delinen bölgelerinin ortasından kesilerek delik yüzeylerin giriș ve çıkışlarından pürüzlülük değerleri ölçülmüştür (Şekil 3). Deneysel tasarım Tablo 2'de gösterilmiştir.

Tablo 2. Deneylerden elde edilen yüzey pürüzlülük değerleri

\begin{tabular}{|c|c|c|c|c|c|}
\hline \multirow{2}{*}{$\begin{array}{l}\dot{\Xi} \\
\grave{\partial} \\
\stackrel{\Xi}{0}\end{array}$} & \multicolumn{3}{|c|}{ Kesme parametreleri } & \multicolumn{2}{|c|}{ Sonuçlar } \\
\hline & $\begin{array}{l}\text { Kesici takımlar } \\
\text { (Çap, Kt, mm) }\end{array}$ & $\begin{array}{l}\text { Kesme hızı } \\
\text { (V, m/dak) }\end{array}$ & $\begin{array}{l}\text { İlerleme oranı } \\
\text { (f, mm/dev) }\end{array}$ & $\begin{array}{c}\text { Yüzey } \\
\text { pürüzlülügü } \\
(\mathrm{Ra}, \mu \mathrm{m})\end{array}$ & $\begin{array}{l}\text { Sertlik } \\
\text { Brinell }\end{array}$ \\
\hline 1 & 6 & 12 & 0.075 & 1.285 & 158 \\
\hline 2 & 6 & 13 & 0.1 & 2.120 & 166 \\
\hline 3 & 6 & 14 & 0.15 & 1.40 & 174 \\
\hline 4 & 7.5 & 12 & 0.1 & 1.685 & 183 \\
\hline 5 & 7.5 & 13 & 0.15 & 1.830 & 178 \\
\hline 6 & 7.5 & 14 & 0.075 & 1.290 & 182 \\
\hline 7 & 9 & 12 & 0.15 & 1.395 & 174 \\
\hline 8 & 9 & 13 & 0.075 & 1.535 & 178 \\
\hline 9 & 9 & 14 & 0.1 & 1.425 & 179 \\
\hline
\end{tabular}

Malzemenin delinmesi esnasında bazı noktalarda takımın zorlandığı ve tınladığı görülmüştür. $\mathrm{Bu}$ nedenle her bir deliğin bulunduğu bölgeden 3 adet olmak üzere Hartip 3000 portatif sertlik ölçme cihazı ile brinell sertlik ölçümleri yapılmıștır. Bu ölçümler Tablo 2'de gösterilmiştir. Teknik kataloglarda yumuşatma tavlaması ile satılan bu çeliğin sertlik değeri yaklaşık olarak 230 HB'ye kadar çlkabildiği ifade edilmiștir [21]. Ancak yapılan ölçümlerde 183 HB'ye kadar çıtığı ve farklı noktalarında farklı sertlik değerlerinin ölçüldüğü görülmüştür. Bu durum delinebilirlik performansına doğrudan etkilidir.

\section{Deneysel Sonuçların Değerlendirilmesi}

\subsection{Pürüzlülük ölçümlerinin değerlendirilmesi}

Delme işlemi sonrası parça deliklerin ortasından kesilerek ölçüme hazır hale getirilmiştir. Ölçümler, deliğin başı ve sonundan olmak üzere iki defa yapılmıștır. Tablo 2'de bu ölçümlerin ortalaması gösterilmiștir. Şekil 3'de pürüzlülük ölçümü yapılan yüzeylerin fotoğrafları ve pürüzlülük ortalamalarına ait grafik verilmiștir. 


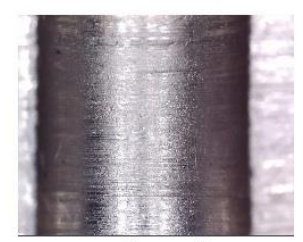

Deney 1

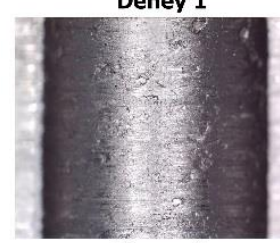

Deney 4

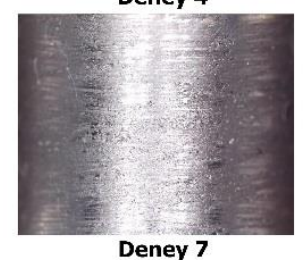

Deney 7

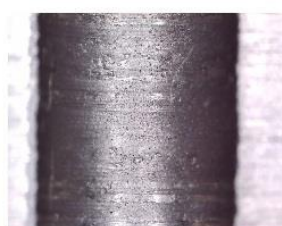

Deney 2

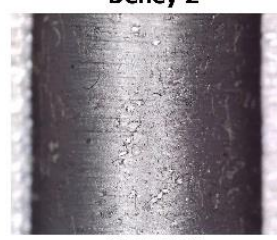

Deney 5

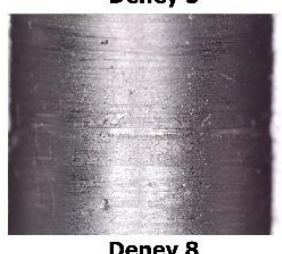

Deney 8

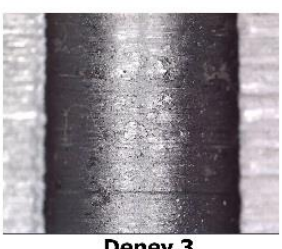

Deney 3

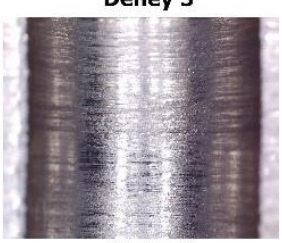

Deney 6

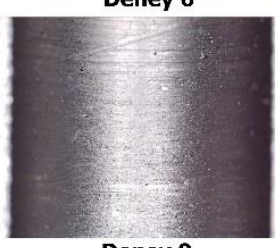

Deney 9

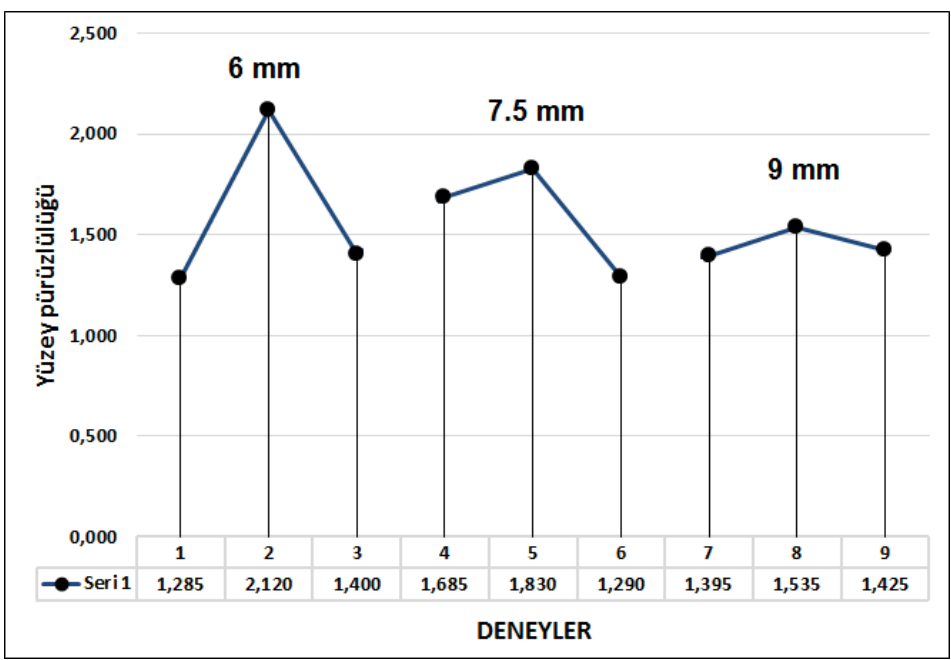

Şekil 3. Pürüzlülük ölçümü için yüzey görüntüleri ve grafiği

Şekil 3'de pürüzlülük ölçümü yapılan yüzeylerin mikroskop ile alınan görüntüleri ve yürütülen deneylerden elde edilen pürüzlülük değerlerinin grafiği gösterilmiştir. Burada 6 mm'lik matkaplarla yapılan ilk üç deney delme işleminde, en iyi pürüzlülük değeri birinci deneyde (12 m/dak ve $0.075 \mathrm{~mm} / \mathrm{dev}$ ) elde edilmiştir. $\mathrm{Bu}$ durum düşük ilerlemeye atfedilmektedir. Ancak 3. Deneyde kesme hızının arttırılması pürüzlülük değerini tekrar düşürmüştür. Dolayısıyla kesme hızının da pürüzlülüğe etkisi olduğu görülmektedir. 7.5 mm matkaplarla yürütülen deneylerde en düşük pürüzlülük değeri, 6 . deneyde $(14 \mathrm{~m} /$ dak, 0.075 $\mathrm{mm} / \mathrm{dev}$ ) elde edilmiștir. $7.5 \mathrm{~mm}$ çaptaki matkapta da pürüzlülüğe kesme hızı ve ilerlemenin etkisi olduğu görülmektedir. $9 \mathrm{~mm}$ çaplı matkap uçlarıyla yürütülen deneylerde ise en düşük pürüzlülük değeri 7 . Deneyde (12 $\mathrm{m} / \mathrm{dak}$ and $0.15 \mathrm{~mm} / \mathrm{dev}$ ) elde edilmiștir. 
DEÜ FMD 23(69), 961-971, 2021

Deneylerde en düşük devir sayısı 7. Deneyde hesaplanmıștır (425 dev/dak). Dolayısıyla 7. Deneyde kullanılan en düşük kesme hızı ve en yüksek ilerleme oranının yanında pürüzlülüğe, düşük devir sayısının yani kesme hızının ve matkap çapının etkisi olduğu düşünülmektedir. Çalışmada, matkap çapı arttıkça yüzey pürüzlülüğün de az miktarda arttığı görülmektedir. $\mathrm{Bu}$ durum, matkap çapının artmasına bağlı olarak devir sayısının azalmasına atfedilmektedir [22]. Genel olarak değerlendirildiğinde ilerleme ve kesme hızının yanında matkap çapı arttıkça devir sayısının da pürüzlülüğe etkisi olduğu görülmektedir. Ayrıca kesme hızının artması pürüzlülük değerini de arttırmıştır. Bu durum kesme hızının artmasıyla birim zamanda oluşan talaş oluşumunun arttığı, bu nedenle talaşın tahliyesinin zorlaşması nedeniyle pürüzlülük değerlerinde artış olmasına atfedilmektedir [7]. Kesme hızı ve ilerlemenin pürüzlülüğe etkisi üç boyutlu grafik ile ayrıca değerlendirilecektir.

\subsection{Așınmaların değerlendirilmesi}

Aşınmaların incelenmesinde, matkap uçlarının diş köşelerinden ve uç kısmından optik mikroskop ile görüntüler alınmıștır. Şekil 4'de 6, 7.5 ve $9 \mathrm{~mm}$ çaplardaki matkaplar için yan yüzey ve uç kısmından 20 kat büyülterek çekilmiş mikroskop görüntüleri gösterilmiştir. Yan yüzey görüntülerinde matkabın zırhı incelenerek dış köşe aşınmalarına bakılmıştır. Uç görüntüleri için radyal aşınmalar incelenmiştir.
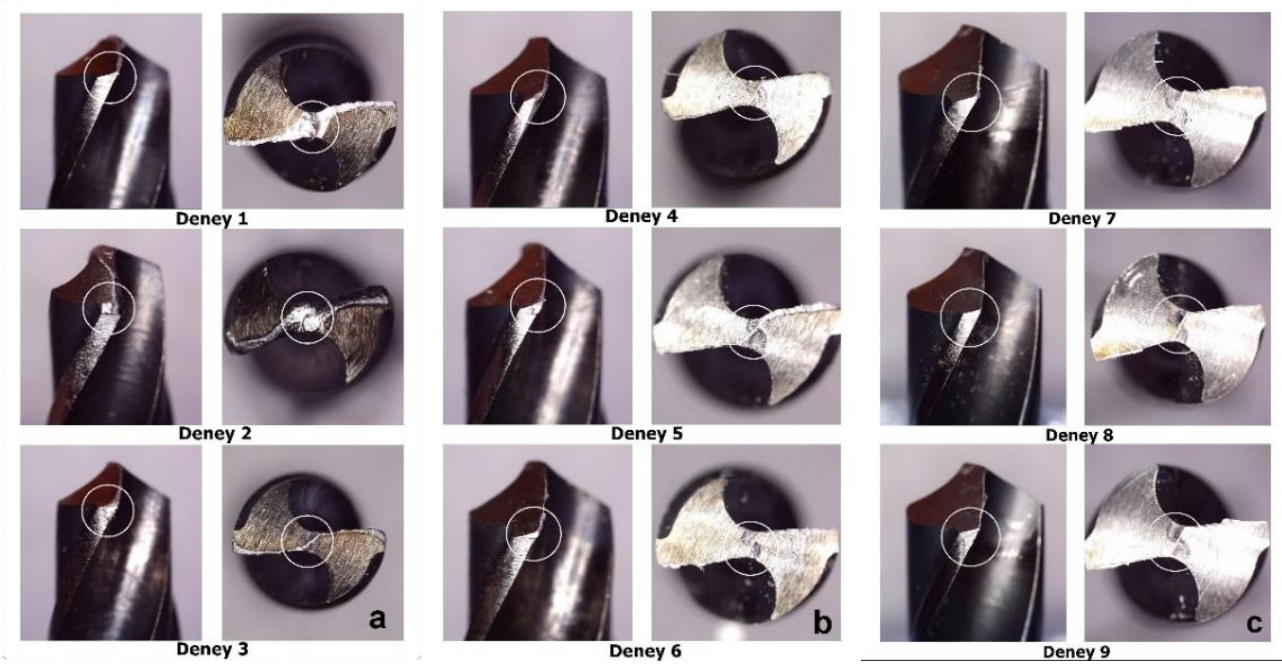

Şekil 4. 6 mm (4a), 7.5 mm (4b) ve 9 mm (4c) çaptaki matkaplara ait dıș köșe ve radyal aşınmaların incelenmesi (Büyültme oranı: 20x)

Yürütülen deneylerde kullanılan malzemenin bazı bölgelerinde sertlik değerlerinin değiștiği gözlemlenmiștir. Deneyler sonrası her bir delik bölgesinden Brinell sertlik ölçümleri yapılmıș ve bu değerler Tablo 2'de gösterilmiştir. Şekil 4 incelendiğinde, 6, 7 ve 9. deneyler hariç diğer deneylerde matkap uçlarında radyal aşınma, 2, 3, 4, 5 ve 9. deneylerde ise diş köşe aşınmasının oluştuğu gözlemlenmiştir. $6 \mathrm{~mm}$ çapındaki matkap ucunda en yüksek radyal aşınma deney $2^{\prime}$ de $(\mathrm{V}=13 \mathrm{~m} / \mathrm{dak}, \mathrm{f}=0.1 \mathrm{~mm} / \mathrm{dev})$ ve $7.5 \mathrm{~mm}$ matkap ile yürütülen deneyler incelendiğinde ise en yüksek radyal aşınma deney 5 'de ( $V=13$ $\mathrm{m} / \mathrm{dak}, \mathrm{f}=0.15 \mathrm{~mm} / \mathrm{dev}$ ) gözlemlenmiștir. $9 \mathrm{~mm}$ çapta matkap ile yapılan deneylerde ise takımlarda radyal aşınma gözlemlenmemiștir. Diğer taraftan $6 \mathrm{~mm}$ çaptaki matkapla yürütülen deneylerde en yüksek dış köşe aşınması 2. deneyde (V=13 m/dak, $\mathrm{f}=; 0.1 \mathrm{~mm} / \mathrm{dev}), 7.5 \mathrm{~mm}$ çaptaki matkaplarla yürütülen deneylerde en yüksek dıș köșe aşınması 5. Deneyde (V=13 $\mathrm{m} / \mathrm{dak}, \mathrm{f}=0.15 \mathrm{~mm} / \mathrm{dev}$ ) ve $9 \mathrm{~mm}$ 'lik matkapla 


\section{DEÜ FMD 23(69), 961-971, 2021}

yürütülen deneylerde en yüksek diș köșe aşınması ise 9. deneyde ( $\mathrm{V}=14 \mathrm{~m} / \mathrm{dak}, \mathrm{f}=0.1$ $\mathrm{mm} / \mathrm{dev}$ ) oluşmuştur. Literatürde delme operasyonlarında, serbest yüzey ve çentik aşınması gibi aşınma türlerinde aşınmaları azaltmak için kesme hızının düşürülmesi ve ilerlemenin azaltılması önerilmektedir [23]. Bu çalışmada kesme hızı ve ilerleme oranları iş parçasının temin edildiği firmanın teknik katalog bilgileri dikkate alınarak belirlenmiştir. İlk delmede aşınmaların oluşması imalatta istenen bir durum değildir. Deneylerde her bir deney için yeni matkap ucu kullanılmıștır. Buna rağmen aşınmaların oluşması nedeniyle bu malzemede kaplaması matkap ucu kullanımı önerilmemektedir.

\subsection{Talaş Oluşumlarının değerlendirilmesi}

Șekil 5'de deneyler esnasında ortaya çıkan talaș oluşumları gösterilmiştir. Bu görüntüler 20 kat büyültme ile alınmıștır. Șekil 5'de deney 1'de, delemeye ilk başlanıldığında spiral talaş oluşumu gözlemlenmiş ancak sonlara doğru yarım kabuk talaşlar çıkmıştır. Genelde kesme ağzında başlayan bu tip talaș, boşaltma kanalı etkisi ile kıvrılır ve bir müddet sonra bu talaş kırılıyorsa kabul edilebilir bir formdur. Delme sonunda oluşan yarım kabuk talaş biçimi ise, boșaltma kanalı ve delik yan duvarları etkisi ile yüksek ilerleme hızlarında olușur [1]. İlk deneyde iki tip talaş oluşumu, malzemenin sertlik açısından homojen bir yapıya sahip olmadığına atfedilmektedir. Toz metalürjik çelik olan bu malzeme yapısında toz partiküllerinin homojen olarak dağılmadığı düşünülmektedir. Şekil 5'de deney 2'de delmenin başından sonuna kadar geçen süreçte yarım kabuk talaş oluşumu gözlemlenmiştir. $\mathrm{Bu}$ durum ilerlemenin artmasına atfedilmektedir. Deney 3'de ise, yine yarım kabuk talaş oluşumu gözlemlenmiş bu durumda da yine artan ilerlemeye bağlıdır. Deney 4'de yolma tip talaş oluşumu gözlemlenmiştir. Yolma talaşlar sarmaya imkân vermeden tahliye edilir ancak bu talaș kolay bir şekilde matkaba dolanabilir $[1,24]$.
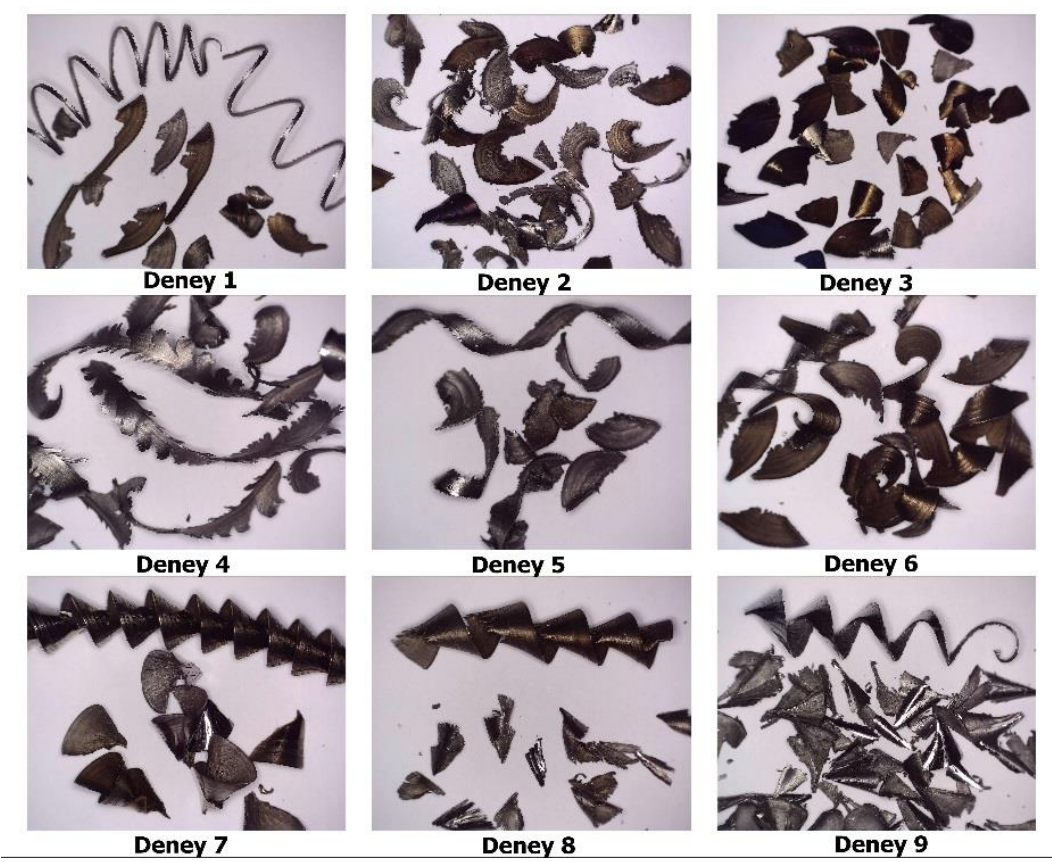

Şekil 5. Her bir deneyden elde edilen talaş oluşumları (Büyültme oranı: 20x) 


\section{DEÜ FMD 23(69), 961-971, 2021}

Şekil 5, Deney 5'de delme başlangıcında yolma talaş oluşumu gözlemlenmiş, sonlara doğru yarım kabuk talaşlar oluşmuştur. Bu durum ilerlemenin artmasına ve malzemenin homojen yapıda olmamasina atfedilmektedir. Deney 6 'da delme işleminin başından sonuna kadar yolma talaş oluşumu gözlemlenmiştir. Deney 7'de deleme başlangıcında spiral tip talaş oluşumu gözlemlenmiştir. Bu tip talaşlar birkaç dakika sonra kırılıyorsa kırılıyorsa kabul edilebilir formdur [1]. Bu deneyde bu talaş biçimi hemen kırılmış daha sonrasında yarım kabuk talaş oluşumu gözlemlenmiştir. Bu durum ilerlemenin artmasına atfedilmiştir. Deney 8'de yine deney 7'de olduğu gibi bașta spiral talaş tipi oluşmuş, sonlara doğru ise yarım kabuk talaş oluşumu gözlemlenmiștir. Deney 9'da ise iğne tip talaş oluşumu gözlemlenmiştir. İğne tipi talaşlar ise titreşim yada gevrek malzemeden dolayı oluşur. Memnuniyet verici bir talaş formudur. Ancak birbirinin üzerine binmesi sebebiyle talaş yığılmasına sebebiyet verebilir [1, 24]. Her bir deneyde farklı talaş formalarının oluşumu, malzemenin sertliğinin farklı yüzeylerde farklı seviyelerde seyretmesine atfedilmektedir.

\subsection{Kesme parametrelerinin yüzey pürüzlülüğüne etkisi}

Deneysel tasarım için seçilmiş olan kesme hızı ve ilerleme oranlarının yüzey pürüzlülük üzerine etkileri üç boyutlu grafikle değerlendirilmiştir. Şekil 6'da kesme hızı ve ilerleme oranının yüzey pürüzlülüğü üzerine etkisi gösterilmiștir.

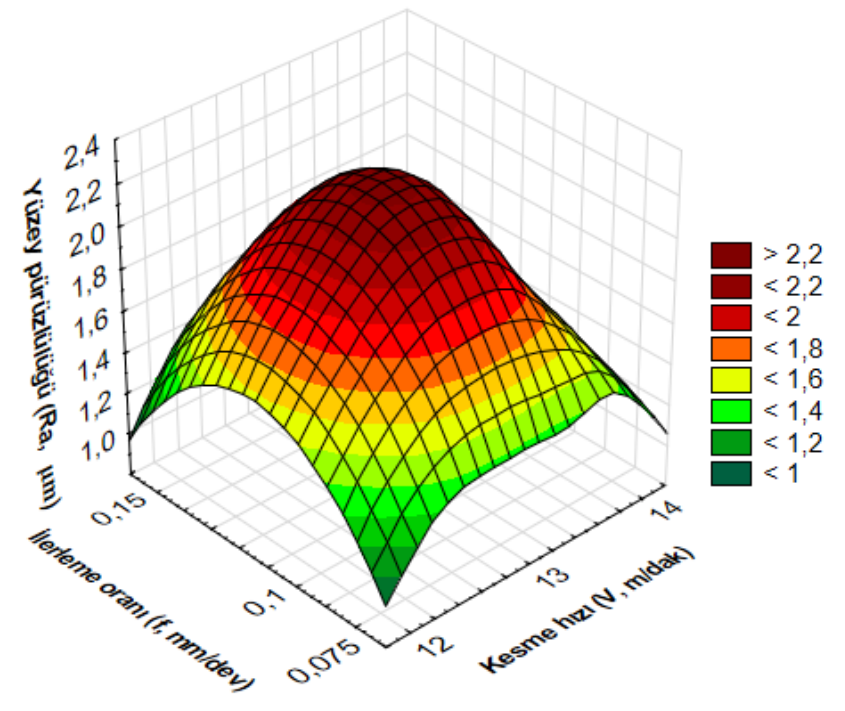

Şekil 6. Kesme hızı ve ilerleme oranının yüzey pürüzlülügüne etkisi

Şekil 6'da ilerleme oranı arttıkça yüzey pürüzlülük değerlerinin arttığg görülmektedir. Ancak pürüzlülük değerlerinin $0.075 \mathrm{~mm} / \mathrm{dev}$ ilerleme oranı ve $12 \mathrm{~m} /$ dak ile $14 \mathrm{~m} /$ dak kesme hızlarında düştüğü görülmektedir. Ayrıca grafikte, ilerleme ve kesme hızı beraber arttıkça pürüzlülüğün de arttığı görülmektedir. Grafikte en yüksek yüzey pürüzlülük değerinin $14 \mathrm{~m} / \mathrm{dak}$ kesme hızı ve $0.15 \mathrm{~mm} / \mathrm{dev}$ ilerleme oranında oluştuğu, en düşük yüzey pürüzlülük değerinin de $12 \mathrm{~m} /$ dak kesme hızı ve $0.075 \mathrm{~mm} / \mathrm{dev}$ ilerleme oranında olduğu görülmektedir.
Deleme operasyonlarında en iyi performans için düşük ilerleme oranı ve düşük kesme hızları pratikte önerilen bir durumdur ve bu durum literatürle benzerlik göstermektedir [23].

\subsection{Etkilerin varyans analizi ile değerlendirilmesi}

Tablo 3'de kesme parametrelerine ait varyans analizi sonuçları verilmiştir. Varyans analizi \%95 güven aralı̆̆ı dikkate alınarak yapılmıștır. 
DEÜ FMD 23(69), 961-971, 2021

Tablo 3. Kesme parametrelerinin varyans analizi ile değerlendirilmesi

\begin{tabular}{lccccc}
\hline Faktörler & $\begin{array}{c}\text { Serbestlik } \\
\text { derecesi (DF) }\end{array}$ & $\begin{array}{c}\text { Kareler } \\
\text { toplamı } \\
\text { (SS) }\end{array}$ & $\begin{array}{c}\text { Kareler } \\
\text { ortalaması } \\
\text { (MS) }\end{array}$ & F & $\begin{array}{c}\text { Faktör } \\
\text { etkisi } \\
(\%)\end{array}$ \\
\hline Kt & 1 & 0.03375 & 0.03375 & 0.30 & 5.43 \\
V & 1 & 0.01042 & 0.01042 & 0.09 & 1.68 \\
f & 1 & 0.01680 & 0.01680 & 0.15 & 2.70 \\
Hata $(e)$ & 5 & 0.56073 & 0.11215 & & 90.19 \\
Toplam & 8 & 0.62170 & & & 100 \\
\hline
\end{tabular}

Tablo 3 incelendiğinde yüzey pürüzlülüğüne etki eden en etkili faktör \% 5.43 ile kesici takım olmuştur. Bu faktörü \%2.70 ile ilerleme oranı takip etmektedir. En düşük etki ise \%1.68 ile kesme hızıdır. Deneylerde üç farklı çapta matkap kullanılması nedeniyle yüzey pürüzlülüğüne etki eden en etkili faktör olarak ilerleme oranının olduğunu söylemek mümkündür.

\subsection{Matematiksel model}

$\mathrm{Bu}$ çalışmada, polynomial regresyon modeli kullanılarak yüzey pürüzlülüğü ve kesme parametreleri arasındaki ilișki matematiksel olarak modellenmiştir. İkinci dereceden regresyon modeli için öngörülen eşitlik aşağıda gösterilmiştir:

$\mathrm{Ra}=-72.41+0.450 \mathrm{Kt}+10.75 \mathrm{~V}+59.2 \mathrm{f}$

$-0.0333 \mathrm{Kt}^{2}-0.4150 \mathrm{~V}^{2}-252.9 \mathrm{f}^{2}$

Regresyon sonuçlarına göre yüzey pürüzlülüğü için elde edilen matematiksel modelin $\mathrm{R}^{2}$ değeri 0.98 (\%98) olarak hesaplanmıștır. Şekil 7'de deneysel olarak elde edilen sonuçlar ve Eșitlik 1 'de verilen matematiksel model sonuçlarının karşılaştırılması gösterilmiştir.

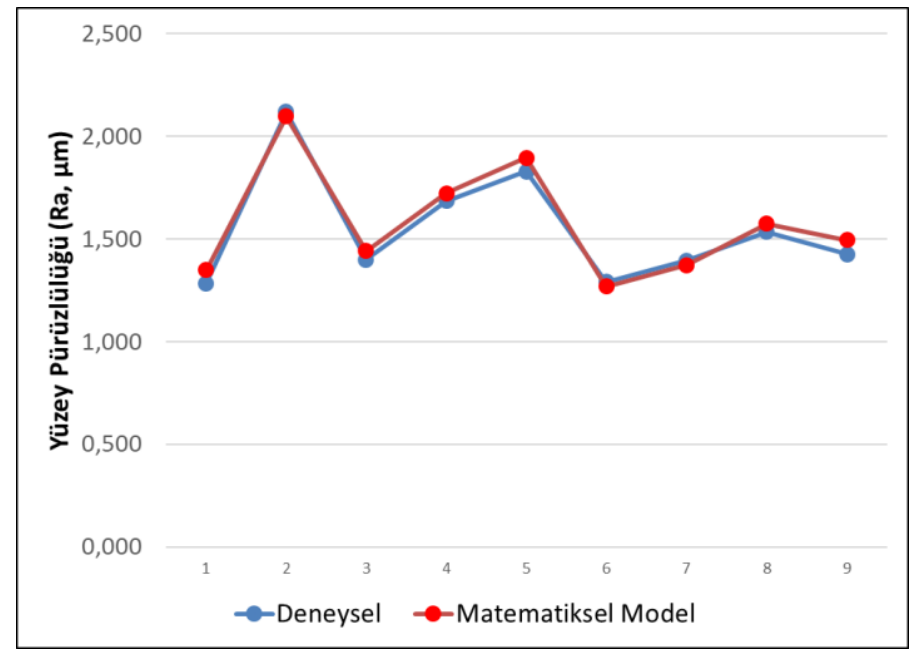

Șekil 7. Deneysel ve matematiksel model sonuçlarının karșılaștırılması

Șekil 7'de görüldüğü gibi deneysel sonuçlar ve matematiksel model sonuçları birbiriyle örtüşmektedir. Dolayısıyla elde edilen matematiksel modelin kullanılabilirliğ uygundur.

\section{Sonuçlar}

Bu çalıșmada üç farklı çapa sahip matkaplar ile üç farklı kesme hızı ve ilerleme oranı kullanılarak Vanadis $4 \mathrm{E}$ toz metalürjik çeliğe delme işlemi uygulanmıștır. Deneysel tasarım 
DEÜ FMD 23(69), 961-971, 2021

için Taguchi L9 ortogonal dizisi kullanılmış ve 9 deney yapılmıştır. Deneysel sonuçlar pürüzlülük görüntülerinin yorumlanması, üç boyutlu grafik ve varyans analizi ile değerlendirilmiştir. Ayrıca polynomial regresyon modeli kullanılarak yüzey pürüzlülüğü için matematiksel model elde edilmiştir. Bu çalışmadan elde edilen sonuçları şu şekilde sıralamak mümkündür;

- Delme esnasında parçanın farklı bölgelerinde tınlamalar oluşmuş ve bunun neticesinde deliklerin yanından sertlik ölçümleri yapılmıştır. Sertlik ölçümleri sonuçlarına göre deney malzemesi farklı sertliklere sahip olduğu görülmüş ve sonuç olarak parça işlenmeden önce gerilim giderme tavı uygulanmasının uygun olacağı düșünülmektedir.

- Yüzey pürüzlülük sonuçları incelendiğinde; $6 \mathrm{~mm}$ 'lik matkaplarla yapılan ilk üç deney delme ișleminde, en iyi pürüzlülük değeri birinci deneyde (12 $\mathrm{m} /$ dak ve $0.075 \mathrm{~mm} / \mathrm{dev}$ ) elde edilmiștir. En yüksek pürüzlülük değeri ise, deney 2'de elde edilmiştir. $7.5 \mathrm{~mm}$ matkaplarla yürütülen deneylerde en düşük pürüzlülük değeri, 6. Deneyde (14 m/dak, 0.075 $\mathrm{mm} / \mathrm{dev}$ ) elde edilmiştir. $9 \mathrm{~mm}$ çaplı matkap uçlarıyla yürütülen deneylerde ise en düşük pürüzlülük değeri 7. Deneyde (12 $\mathrm{m} /$ dak and $0.15 \mathrm{~mm} / \mathrm{dev}$ ) elde edilmiştir.

- Üç boyutlu grafik değerlendirildiğinde, kesme hızı ve ilerleme oranının artması pürüzlülük değerini de arttırmaktadır. Kesme parametreleri malzeme teknik kataloğundan seçildiği düşünülürse, bu malzeme için kaplamasız matkaplarla yapılan delme işleminde $12 \mathrm{~m} /$ dak kesme hızı ve $0.075 \mathrm{~mm} / \mathrm{dev}$ ilerleme oranının kullanılması önerilmektedir.

- Talaş oluşumları incelendiğinde spiral, yolma talaş, yarım kabuk ve iğne tipinde talaşların oluştuğu görülmüş bu durum da malzemenin farklı sertlik değerlerine atfedilmiştir.

- Yüzey pürüzlülüğü için yapılan varyans analizinde en etkili parametre ilerleme oranı olmuştur. Burada üç farklı çapta matkap kullanıldığı için kesici takım değerlendirmeye alınmamıștır.
Yapılan bu çalışmada kullanılan Vanadis 4E çeliğinin delinmesi öncesi gerilim giderme tavı uygulanarak iç gerilmelerin giderilmesi önerilmektedir. Ayrıca deneyler sonrası aşınmalar incelendiğinde gerek dış köşe gerekse radyal aşınmaların oluşması nedeniyle bu malzeme için delme ișlemlerinde kaplamasız kesici takımların kullanılması önerilmemektedir. Sonraki çalışmalarda bu malzemenin farklı kesme parametreleri ile yüzey frezeleme, cep frezeleme ve kanal frezeleme ișlemleri yapılarak işleme performansı test edilebilir.

\section{Kaynakça}

[1] Yavuz, M., Gökçe, H., Șeker, U. 2017. Investigation of the effect of drill geometry on tool wear and chip formation, Gazi Journal of Engineering Science, Cilt. 3(1), s. 11-19.

[2] Bayraktar, Ș., Siyambaș, Y., Turgut, Y. 2017. Delik delme prosesi: bir araștırma, Sakarya University Journal of Science, Cilt. 21(2), s. 120-130. DOI: 10.16984/saufenbilder.296833

[3] SreeramaReddy, T.V., Sornakumar, T., VenkataramaReddy, M., Venkatram, R. 2009. Machinability of C45 steel with deep cryogenic treated tungsten carbide cutting tool inserts. Int. J. Refract Metal Hard Mater., Cilt. 27, s. 181-185. DOI: 10.1016/j.ijrmhm.2008.04.007

[4] Khan, A.A., Ahmed, M.I. 2008. Improving tool life using cryogenic cooling. J Mater Process Technol Cilt. $196 \quad(1-3), \quad$ s. 149-154. DOI: 10.1016/j.jmatprotec.2007.05.030

[5] Ciçek, A., Kıvak, T., Uygur, İ., Ekici, E., Turgut, Y. 2012. Performance of cryogenically treated M35 HSS drills in drilling of austenitic stainless steels, Int J. Adv Manuf Technol, Cilt. 60, s. 65-73. DOI: 10.1007/s00170-011-3616-8

[6] Çiçek, A., Ekici, E., Uygur, İ., Akıncıoğlu, S., Kıvak, T. 2012. AISI D2 soğuk iș takım çeliğinin delinmesinde derin kriyojenik ișlemin takım ömrü üzerindeki etkilerinin araştırılması, SDU International Journal of Technological Science, Cilt. 4 (1), s. 1-9.

[7] Yavuz, M., Gökçe, H., Yavaş, Ç., Korkut, İ., Şeker, U. 2017. Effect of drill geometry on hole quality and cutting performance, Sakarya University Journal of Science, Cilt. 21 (5), s. 1051-1066. DOI: 10.16984/saufenbilder.292019

[8] Kıvak, T., Çiçek, A., Uygur, İ., Özbek, N. A. 2012. AISI 316 Östenitik paslanmaz çeliğin delinmesinde tek katlı ve çok katlı kaplamaların delik kalitesi üzerindeki etkileri, 3. Ulusal Talaşlı İmalat Sempozyumu, 04-05 Ekim, Ankara.

[9] Yağmur, S., Çakıroğlu, R., Acır, A., Şeker, U. 2017. The optimization of thrust force in drilling operation on 


\section{DEÜ FMD 23(69), 961-971, 2021}

AISI 1050 steel with Taguchi Method, GU J. Sci, Part C, Cilt. 5(2), s. 241-246.

[10] Yağmur, S., Acır, A., Şeker, U., Günay, M. 2013. Delik delme işlemlerinde kesme parametrelerinin kesme bölgesindeki sıcaklığa etkisinin deneysel incelenmesi, Gazi Üniversitesi Mühendislik Mimarlık Fakültesi Dergisi, Cilt. 28 (1), s. 1-6.

[11] Meral, T., Günay, M. 2019. Kaplamalı ve kaplamasız karbür matkap ile ferritik paslanmaz çeliğin delinebilirlik analizi, Gazi Mühendislik Bilimleri Dergisi Cilt. 5(2), s. 159-166. DOI: 10.30855/gmbd.2019.02.05

[12] Rasti, A., Sadeghi, M. H., Farshi, S. S. 2019. An investigation into the effect of surface integrity on the fatique failure of AISI 4340 steel in different drilling strategies, Engineering Failure Analysis, Cilt. 95, s. 66-81. DOI: $10.1016 / \mathrm{j}$.engfailanal. 2018.08.022

[13] Çakıroğlu, R., Acır, A. 2013. Al2014 malzemesinin delinmesinde takım talaş ara yüzey sıcaklıkları ve kesme kuvvetinin Taguchi metodu ile optimizasyonu, Makine Teknolojileri Elektronik Dergisi, Cilt. 10(2), s. 73-86.

[14] Varatharajulu, M., Jayaprakash, G., Baskar, N., Suresh Kumar, B., Kannan, S., Haja Maideen, A. 2020. Evaluation of desirability function approach and genetic algorithm optimization of drilling characteristics on Duplex 2205, Materials Today: Proceedings, Cilt. 22(3), s. 589-600 DOI: 10.1016/j.matpr.2019.08.225

[15] Mudhukrishnan, M., Hariharan, P., Palanikumar, K. 2020. Measurement and analysis of thrust force and delamination in drilling glass fiber reinforced polypropylene composites using different drills, Measurement, Cilt. 149, s. 1-10. DOI: 10.1016/j.measurement.2019.106973

[16] Arif, R., Fromentin, G., Rossi, F., Marcon, B., Blandener, P. 2018. Mechanical study in drilling of heat resistant austenitic stainless steel, Procedia CIRP, Cilt. 77, s. 425-428. DOI 10.1016/j.procir.2018.08.292

[17] Ankalagi, S., Gaitonde, V. N., Petkar, P. 2017 Experimental studies on hole quality in drilling of SA182 steel, Materials Today: Proceedings, Cil. $4(10)$, s. 11201-11209. DOI: 10.1016/ j.matpr.2017.09.041

[18] Upputuri, H. B., Nimmagadda, V. S. 2020 Optimization of drilling process parameters used in machining of glass fiber reinforced epoxy composite, Materials Today: Proceedings, Cilt. 23(3), s. 594-599 DOI: 10.1016/j.matpr.2019.05.415.

[19] Sultan, A. Z., Sharif, S., Nor, F. M. 2019. Kurniawan D., Minimum quantity of lubricant drilling of stainless steel using refined palm olein: Effect of coating tool on surface roughness and tool wear, Procedia Manufacturing Cilt. 30, s. 427-434. DOI: 10.1016/j.promfg.2019.02.059.

[20] Miklos, M., Holubjak, J., Drbul, M., Danis, İ., Czanova, T., Pilc, J. 2019. Idendification of tool wear drilling process of bearings steels C56E2 with microstructure of lamellar pearlite, Transportation Research Procedia, Cilt. 40, s. 381-388. DOI: 10.1016/j.trpro.2019.07.056.

[21] Uddeholm, 2019. Vanadis 4 Extra cutting data recommendations.

[22] Doğru, N. 2010, AISI çelik malzemenin sürtünmeli delme yöntemiyle delinmesinde delme karakteristiklerinin araștırılması, Yüksek Lisans Tezi, Fırat Üniversitesi, s. 43.

[23] Yaldız, S., Takım așınma mekanizmaları ve așınma tipleri, ders notları, Selçuk Üniversitesi, Konya

[24] Çakır, M.C., Oran, A., Türker, Y.E. 2013. Sert Malzemelerin Delinmesi İşleminde Kaplama Tiplerinin ve İşleme Parametrelerinin Delme İslemine Etkilerinin İncelenmesi. 4. Ulusal Talaşlı İmalat Sempozyumu, Kuşadası. 